\title{
Evolution Mechanism of Interconnected Vertical Fractures in the Overburden of Longwall Coal Mining
}

\author{
He Changchun $\mathbb{D}^{1},{ }^{1}$ Lu Weiyong $\mathbb{D},{ }^{2}$ and Zha Wenhua ${ }^{1}$ \\ ${ }^{1}$ School of Civil Engineering and Architecture, East China University of Technology, Nanchang, Jiangxi 330013, China \\ ${ }^{2}$ Department of Mining Engineering, Luliang University, Lvliang, Shanxi 033001, China
}

Correspondence should be addressed to He Changchun; hechangchun87@126.com and Lu Weiyong; 489698551@qq.com

Received 11 June 2020; Revised 17 July 2020; Accepted 20 October 2020; Published 19 November 2020

Academic Editor: Yingchun Li

Copyright (C) $2020 \mathrm{He}$ Changchun et al. This is an open access article distributed under the Creative Commons Attribution License, which permits unrestricted use, distribution, and reproduction in any medium, provided the original work is properly cited.

\begin{abstract}
Whether a tensile failure fracture will penetrate a stratum is difficult to ascertain at present. In view of this, the method of similar simulation and field verification are used to carry out a systematic study. Similar simulations show that tensile failure fractures will penetrate the layered strata if the compressive stress is greater than the compressive strength. Theoretical analysis points out that whether the tensile failure fractures will penetrate the layered strata can be expressed by the value of criterion of interconnected vertical fractures and the compression-tension ratio. When the value of criterion of interconnected vertical fractures is greater than the compression-tension ratio, the layered strata will break. This criterion was qualitatively verified with a field test. The results of this paper are of great significance for the prevention of water inrush in coal mines, and it can also promote the understanding of the law of strata movement.
\end{abstract}

\section{Introduction}

China is a large coal resource country and also a large coal consumption country. Most of the energy supply comes from coal. In 2019, coal still accounts for about $60 \%$ of the primary energy consumption ratio [1]. However, a large number of coal mining will also bring many negative impacts, such as ecological damage, surface subsidence, gas outburst, and mine water inrush [2-5]. Mine water inrush is usually fierce, often submerging working faces and tunnels in a short time, bringing harm to mine production and causing casualties. The necessary conditions for mine water inrush are adequate water source and water inrush passage. Most of the mining areas in China are located under the water-rich Quaternary loose aquifer, in which mine water inrush resources are sufficient to meet the source conditions of mine water inrush. The water inrush channel is divided into the primary channel and the secondary channel, and the former channel includes fault, karst, etc. $[6,7]$. The secondary channel is the horizontal and mining-induced interconnected vertical fractures [8-
12]. Because the horizontal fractures cannot connect the working face and the aquifer alone, interconnected vertical fractures are the secondary channel of mine water inrush.

After coal seam mining, the overburden is usually divided into the caving zone, the fracture zone, and the bending zone according to the different fracture states [13-19]. Among them, the caving zone has a high degree of fracture development, disordered fracture distribution, and strong permeability, while there are mainly horizontal fractures and interconnected vertical fractures in the fracture zone. Since both the caving zone and the fracture zone have the ability to conduct water, the range of both is the water-flowing fracture zone, and its range is shown in Figure 1. The strata in the bending zone subside as a whole without horizontal fractures or interconnected vertical fractures. If there is a stratum in the bending zone located between the water-flowing fracture zone and the aquifer, the water in the aquifer lacks a transport channel and the water source will not inflow into the coal mining faces. But when interconnected vertical fractures directly develop into the aquifer, the coal mining faces will 


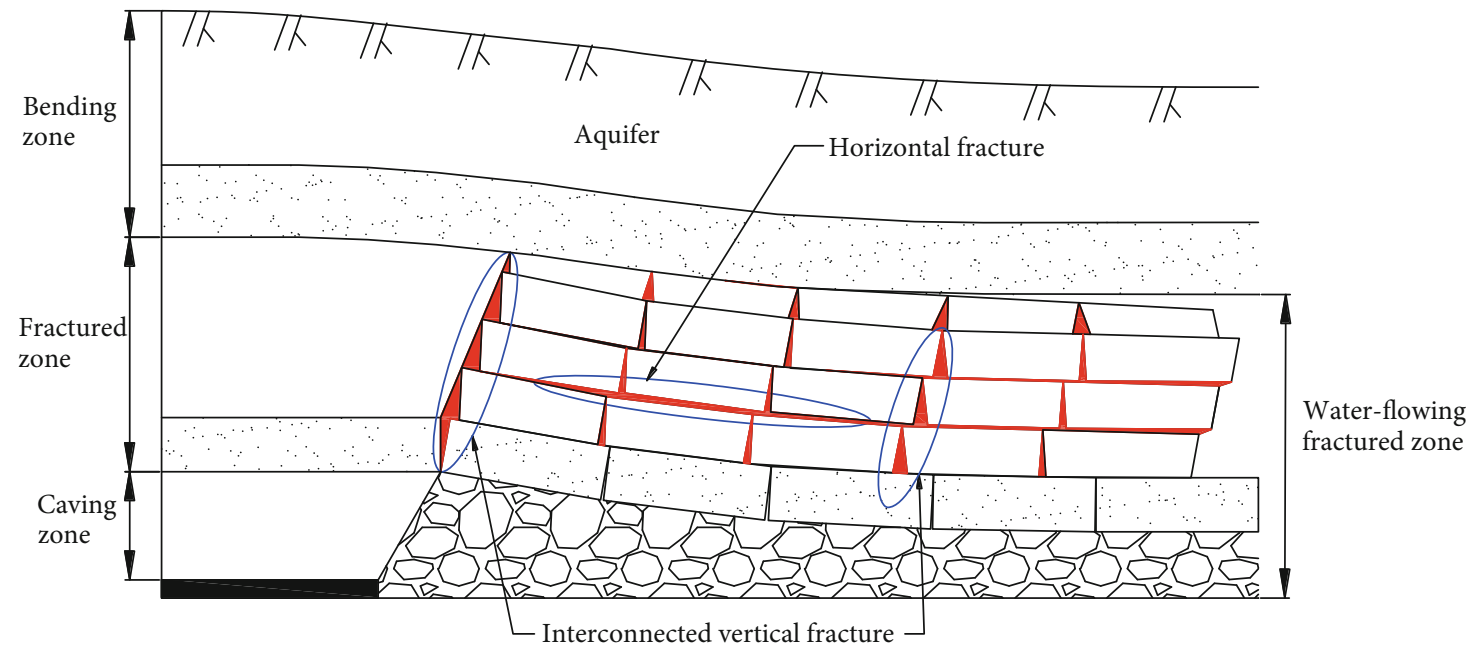

Figure 1: Distribution diagram of overburden fracture after coal seam mining.

suffer the threat of water inrush and protective measures should be taken.

In view of the height of interconnected vertical fractures in the overburden, many scholars have carried out researches from different aspects. Wang et al. [20, 21] proposed the "void ratios of fractures" to quantify the separation and fracture evolution in the undermined overburden. On the basis of a lot of practical experience, the former Soviet Union and China put forward several statistical formulae for calculating the height of interconnected vertical fractures and formed a standard [22]. However, the failure characteristics of the overburden under certain special conditions cannot be reflected by the standard formula, by which the measured height of interconnected vertical fractures is significantly higher than that estimated by the standard formula, which leads to many abnormal water inrush accidents [23]. Given the shortcomings of the standard formula, Xu et al. [24, 25] proposed a formula for predicting the height of interconnected vertical fractures based on the position of the primary key strata (PKS), considering the fact of the layered characteristics of overburden and the fracture characteristics of different lithologies. But it is still essentially an empirical formula. There are many mining and geological factors that affect the height of interconnected vertical fractures. Numerous scholars have made predictions of the height of interconnected vertical fractures based on the theory of influencing factors [26-29], which need a large number of measured data, and whether they are universal remains to be verified. The actual measurement method is a direct and effective method for determining the height of interconnected vertical fractures in the overburden. It is generally observed by means of ground drilling $[9,30]$, as well as other test methods based on modern equipment [31]. These methods can predict the height of interconnected vertical fractures in overburden to a certain extent, but no mechanical mechanism of rock breakage has been involved, and the breaking of a stratum is essentially a result of stress caused by the external environment that exceeds the bearing capacity of the stratum itself. The novelty of this paper is that when a tensile failure fracture will penetrate a stratum is proposed.
In this paper, the characteristics of interconnected vertical fractures in layered strata are firstly studied by similar simulation, and then under certain simplified conditions, the discrimination formula of interconnected vertical fractures in layered strata is obtained by theoretical deduction and calculation. Thirdly, the breaking of each stratum is carried out according to the overburden histogram, and the discriminant method of the height of the water-flowing fracture zone in the overburden is obtained. Finally, the discrimination formula of interconnected vertical fractures is qualitatively verified by an engineering test.

\section{Discrimination Formula for Interconnected Vertical Fractures}

\subsection{Characteristics of Interconnected Vertical Fractures}

2.1.1. Model Design. The gravitational planar stress model frame was used in this study to simulate the characteristics of interconnected vertical fractures. The dimensions of the model were $250 \mathrm{~cm} \times 20 \mathrm{~cm}$. In the material mix for each rock layer, sand was used as the aggregate, while plaster and calcium carbonate were used as cements. A layer of mica was placed in the interfaces between the strata to simulate stratification, and the thickness of the soft rock strata was $6-8 \mathrm{~cm}$. The excavation was in steps of $2.5 \mathrm{~cm}$. The simulation was imaged after each excavation to compare the strata breakage and movement before and after the excavation. The mixing ratios that were used are shown in Table 1.

2.1.2. Experimental Results. The distribution of vertical fractures is shown in Figure 2, from which two characteristics of layered strata failure can be found: (1) The mininginduced vertical fractures do not necessarily penetrate the entire thickness of layered strata, that is, the fractures are in a critical state when they extend to a certain extent. The reason for these fractures is that the tensile stress is greater than the tensile strength of the layered strata. (2) Compressive failure occurs at the upper end of the layered strata penetrated by fractures, which indicates that the critical condition for 
TABLe 1: Proportion of the similar simulation materials.

\begin{tabular}{|c|c|c|c|c|c|c|}
\hline Rock strata & Thickness $(\mathrm{cm})$ & Material ratio & Sand $(\mathrm{kg})$ & $\begin{array}{c}\text { Similar mater } \\
\mathrm{CaCO}_{3}(\mathrm{~kg})\end{array}$ & Gypsum (kg) & Water $(\mathrm{kg})$ \\
\hline Soft rock & 8 & 473 & 38.4 & 6.72 & 2.88 & 4.8 \\
\hline Primary key stratum & 12 & 437 & 30 & 2.25 & 5.25 & 3.75 \\
\hline Soft rock & 6 & 473 & 28.8 & 5.04 & 2.16 & 3.6 \\
\hline Soft rock & 6 & 473 & 30 & 5.25 & 2.25 & 3.75 \\
\hline Soft rock & 6 & 473 & 28.8 & 5.04 & 2.16 & 3.6 \\
\hline Soft rock & 6 & 473 & 40 & 7 & 3 & 5 \\
\hline Soft rock & 8 & 473 & 38.4 & 6.72 & 2.88 & 4.8 \\
\hline Soft rock & 6 & 473 & 30 & 5.25 & 2.25 & 3.75 \\
\hline Soft rock & 6 & 473 & 28.8 & 5.04 & 2.16 & 3.6 \\
\hline Soft rock & 6 & 473 & 30 & 5.25 & 2.25 & 3.75 \\
\hline Soft rock & 6 & 473 & 28.8 & 5.04 & 2.16 & 3.6 \\
\hline Soft rock & 6 & 473 & 75 & 13.125 & 5.625 & 9.375 \\
\hline Hard rock & 15 & 455 & 72 & 9 & 9 & 9 \\
\hline Key stratum 2 & 14 & 455 & 40 & 5 & 5 & 5 \\
\hline Soft rock & 8 & 473 & 38.4 & 6.72 & 2.88 & 4.8 \\
\hline Soft rock & 6 & 473 & 30 & 5.25 & 2.25 & 3.75 \\
\hline Soft rock & 6 & 473 & 28.8 & 5.04 & 2.16 & 3.6 \\
\hline Soft rock & 6 & 473 & 55 & 9.625 & 4.125 & 6.875 \\
\hline Key stratum 1 & 11 & 455 & 52.8 & 6.6 & 6.6 & 6.6 \\
\hline Soft rock & 6 & 473 & 20 & 3.5 & 1.5 & 2.5 \\
\hline Immediate roof & 4 & 473 & 19.2 & 3.36 & 1.44 & 2.4 \\
\hline Coal seam & 7 & 773 & 82.03125 & 8.203125 & 3.515625 & 9.375 \\
\hline Floor & 15 & 455 & 72 & 12.6 & 5.4 & 9 \\
\hline
\end{tabular}

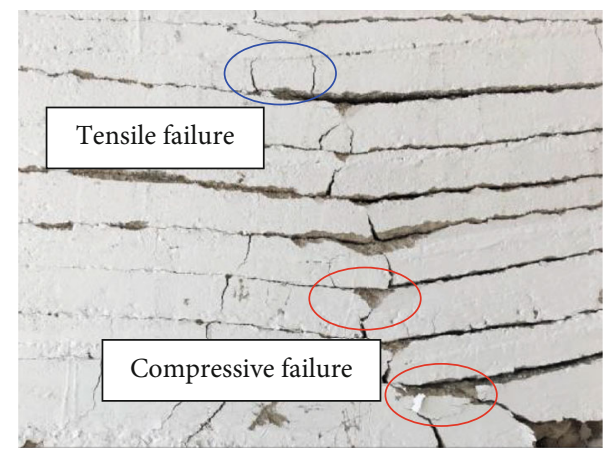

FIGURE 2: Characteristics of vertical fractures in simulated layered strata.

strata breakage is that the compressive stress reaches the compressive strength.

To further illustrate the above two characteristics of layer breakage, a schematic analysis of vertical fracture initiation and propagation is performed. The longitudinal stress development of vertical fracture propagation is shown in Figure 3, and the stress at the crack tip is only for the purpose of display and does not represent the true stress. In addition, $h$ is the thickness of layered strata, $\sigma_{\mathrm{t}}$ is the tensile strength, and $\sigma_{c}$ is the compressive strength. (1) When the longitudinal tensile stress and compressive stress caused by external factors are small, according to material mechanics theory, the tensile stress and compressive stress are equal and the neutral plane coincides with the central plane, as shown in Figure 3(a). (2) When the change of external factors causes the longitudinal tensile stress and compressive stress to increase, because the compressive strength is greater than the tensile strength, the longitudinal tensile stress will first reach the tensile strength, that is, the rock has a tensile failure fracture, as shown in Figure 3(b). (3) When the external factors continue to change, the vertical fracture begins to expand, and the longitudinal tensile stress at the crack tip has always been equal to the tensile strength, and because the compressive stress is less than the compressive strength, the longitudinal compressive stress continues to increase, as shown in Figure 3(c). (4) When the longitudinal compressive stress increases to the compressive strength, the compressive end of the stratum enters into the plastic state, and the end unit cannot limit the rotation of the section. Therefore, the stress-strain equilibrium state at the crack tip is destroyed, causing the expansion of the fracture, and the subsidence of the stratum also increases, so that more end units in the critical state enter into the plastic state, which is a vicious cycle until the vertical fracture penetrates the stratum, as shown in Figure 3(d).

\subsection{Discrimination Formula for Interconnected Vertical} Fractures. In order get applicable results, the following assumptions are made: 


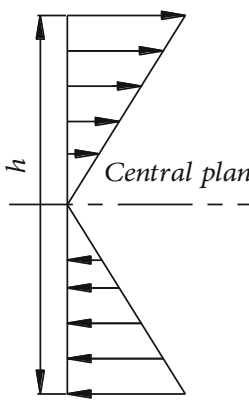

(a)

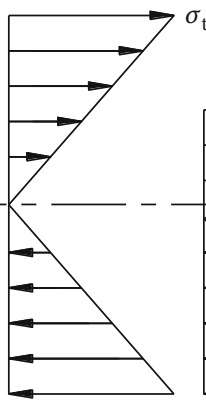

(b)

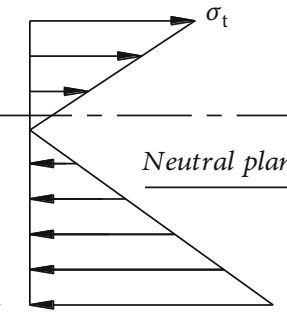

(c)

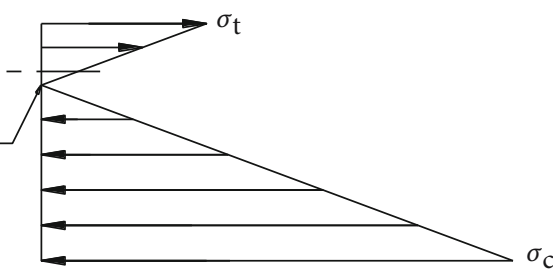

(d)

Figure 3: Longitudinal stress change in fracture section of the stratum.

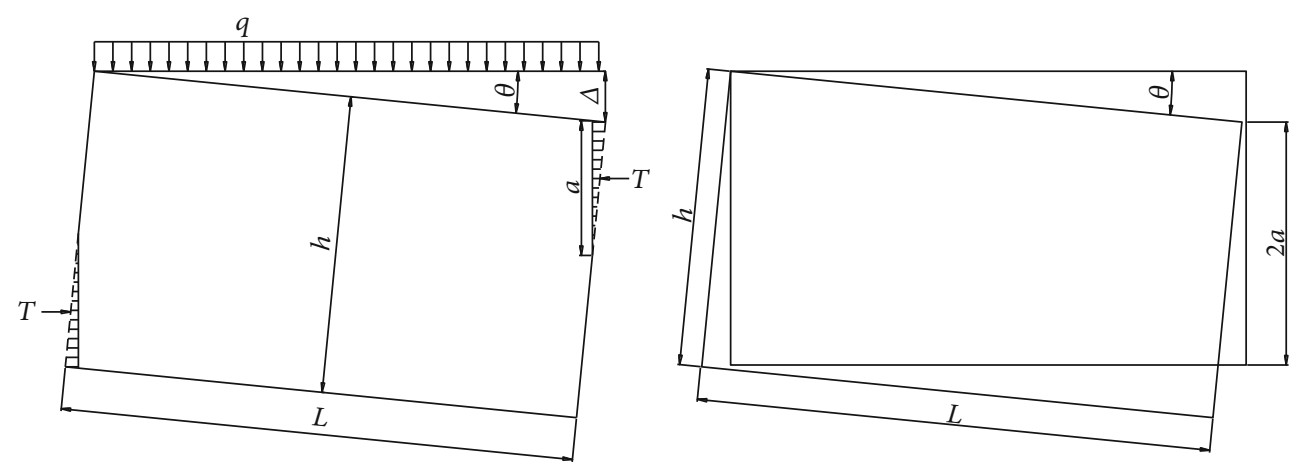

FIGURE 4: Equivalent model of layered strata in the period of first breaking.

(1) The deposit and rock layers are horizontally stratified

(2) There is no major geological structural damage to the deposit and rock layers

(3) The strata are transversely isotropic linear elastomers

(4) The layered strata are broken into two symmetrical blocks

(5) A stratum in the plane is simplified as a fixed beam at both ends

According to the above-mentioned characteristics of interconnected vertical fractures of layered strata, when the layered strata rotates to a certain level, under the action of bending moment and axial force, the longitudinal compressive stress at the end of the strata reaches the compressive strength, and the vertical tensile fractures will penetrate the layered strata. When the layered strata are broken for the first time, the cross-sectional shear force in the middle part of the symmetrical strata is zero, which is equivalent to cutting the layered strata with interconnected vertical fractures here. Before the strata break, the stratum will separate with the lower one and only the load will act on the upper surface of the stratum. Therefore, the equivalent model can be represented in Figure 4 where the tensile stress is ignored because it is much smaller compared with the compressive stress. The load $q$ on the layered strata includes the load from the upper strata and self-weight, $T$ is the resultant force of the compressive stress at the extrusion, $a$ is the range of the compressive stress at the extrusion, $h$ is the thickness of the layered strata, $L$ is the length of the breaking blocks, $\theta$ is the rotation angle of the blocks, and $\Delta$ is the maximum relative subsidence at the end of the blocks caused by rotation, then the load $T$ can be calculated in the equivalent model [32]:

$$
T\left(h-\frac{2 a}{3}-\Delta\right)=\frac{q L^{2}}{2}
$$

When a fracture penetrates a stratum, the range of compressive stress action at the extrusion can be expressed by the thickness of the rock layer according to the geometrical relationship between the blocks, and the range of compressive stress at the extrusion can be obtained [33]:

$$
a=\frac{2 h-\Delta}{4}
$$

Combined with (1) and (2), horizontal forces during rock block rotation can be obtained:

$$
T=\frac{3 q L^{2}}{4 h-5 \Delta} .
$$

According to the process analysis of the abovementioned layered stratum fracturing, when the end unit of the layered stratum extrusion enters the plastic state (the compressive stress generated by horizontal thrust is greater than the compressive strength), the layered strata will be 


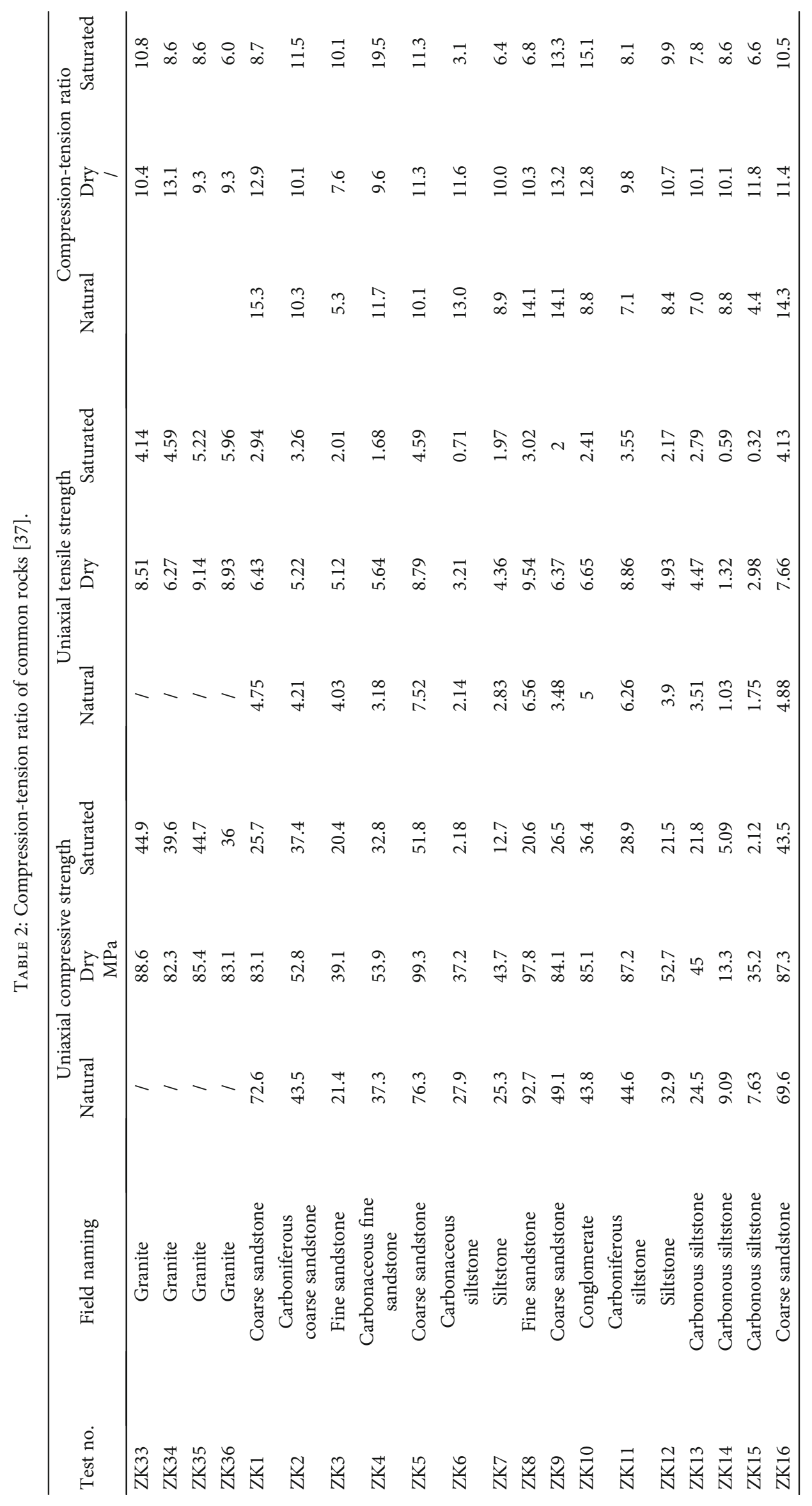




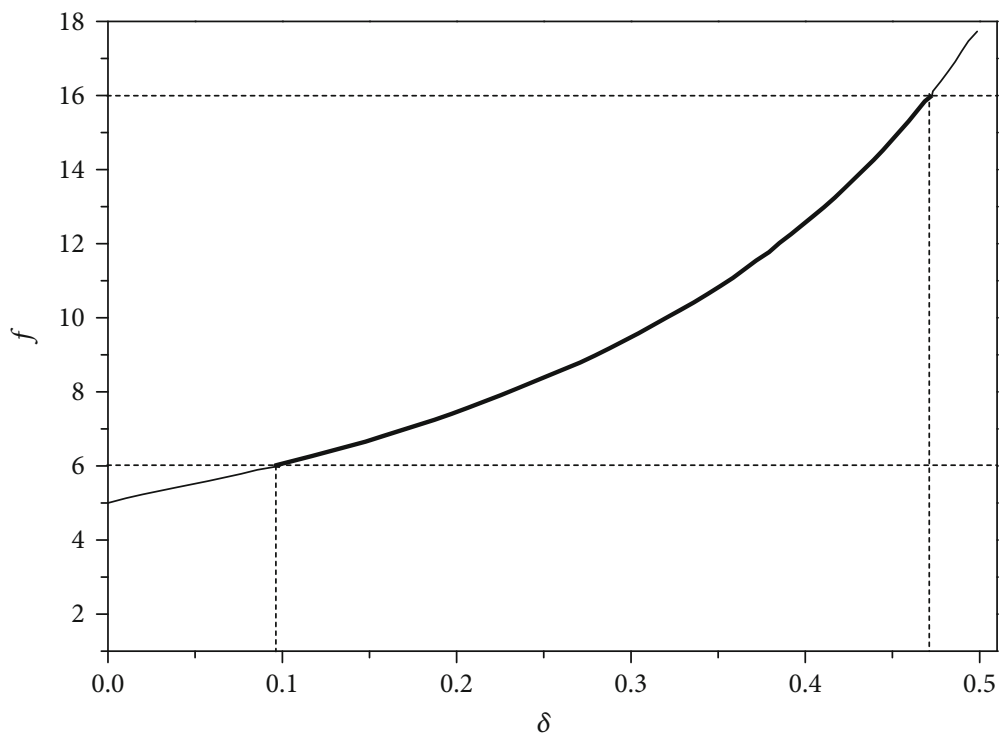

Figure 5: Criterion values for different deflection-thickness ratios.

penetrated by the vertical fractures, namely,

$$
\frac{24 q L^{2}}{(4 h-5 \Delta)(2 h-\Delta)} \geq \eta \sigma_{c}
$$

where $\eta$ is the extrusion strength coefficient at the end, which is usually 0.3 [34]. According to the fifth hypothesis, the breaking length of rock blocks can be obtained from the relationship between the rock load and tensile strength of the two-end fixed beam in the ultimate bending state, which is

$$
L=\frac{h}{2} \sqrt{\frac{2 \sigma_{\mathrm{t}}}{q}} .
$$

The discrimination formula of interconnected vertical fractures of layered strata is obtained by combining formulae (4) and (5), which is

$$
\frac{40 h^{2}}{(4 h-5 \Delta)(2 h-\Delta)} \geq \frac{\sigma_{\mathrm{c}}}{\sigma_{\mathrm{t}}},
$$

where $\Delta$ is the centre subsidence relative to the fixed end of the block and $\sigma_{\mathrm{c}}$ and $\sigma_{\mathrm{t}}$ are the uniaxial compressive and tensile strengths of the rock, respectively. The right side of formula (6) is the ratio of compressive stress to tensile stress of layered strata mass (compression-tension ratio). Brook believed that the compression-tension ratio of sandstone is 15 [35], and Sheorey by statistics obtains that the compression-tension ratio of sandstone is between 7 and 39 , with an average of 14.9 [36]. Sun [37] has tested the compression-tension ratio of common rocks with different water contents. The measured results are shown in Table 2. The compression-tension ratio of rock blocks in the laboratory is about 10 , and in general, the compressive strength of dried rock $>$ natural rock $>$ saturated rock.

\section{Height of Water-Flowing Fracture Zone in the Overburden}

3.1. Maximum Relative Subsidence. The deflection-thickness ratio $\delta$ is defined as the ratio of the maximum relative subsidence of the strata to the thickness of the layered strata. Then, the left side (criterion value) of formula (6) becomes

$$
f(\delta)=\frac{40}{(4-5 \delta)(2-\delta)}
$$

The relationship between function $f$ and $\delta$ is shown in Figure 5. It indicates that the greater the deflectionthickness ratio (maximum relative subsidence), the easier it is for the strata to break and vice versa. The maximum relative subsidence of hard rock is directly related to the mining height and bulking coefficient and is directly proportional to the mining height and inversely proportional to the bulking coefficient. In addition, it can be seen from the range of the rock compression-tension ratio that fractures will vertically penetrate the layered strata in the area indicated by the thick black line in Figure 5.

The key of equation (7) is to calculate the deflectionthickness ratio that is composed of the thickness and the maximum relative subsidence of layered strata. The thickness of layered strata can be obtained from the borehole histogram, which is an easy parameter to get. The maximum relative subsidence is equal to the mining height subtracting the bulking height of the caving zone and the unloading dilation of the layered strata above the caving zone, which are explained separately below.

3.1.1. Bulking Height of the Caving Zone. The bulking height $h_{\mathrm{p}}$ of the caving zone is determined by the height $H_{\mathrm{k}}$ of the caving zone and the bulking coefficient $K_{\mathrm{p}}$. The height of the caving zone is generally determined by actual measurement. When no measured data is available, the height can 
TABLE 3: Empirical formula for calculating the height of caving zone.

\begin{tabular}{lr}
\hline Lithology of overburden (uniaxial compressive strength and main rock name) (MPa) & Calculation formula (m) \\
\hline Hard (40-80, quartz sandstone, limestone, conglomerate) & $(100 M / 2.1 M+16) \pm 2.5$ \\
Medium-hard (20-40, sandstone, argillaceous limestone, sandy shale, shale) & $(100 M / 4.7 M+19) \pm 2.2$ \\
Weak (10-20, mudstone, argillaceous sandstone) & $(100 M / 6.2 M+32) \pm 1.5$ \\
Very weak $(<10$, bauxite, weathered mudstone, clay, sandy clay) & $(100 M / 7.0 M+63) \pm 1.2$ \\
\hline
\end{tabular}

TABle 4: Coefficient of crushing and swelling of loose rock (coal).

\begin{tabular}{|c|c|c|c|c|c|}
\hline Rock & $\varphi \leq 0.5$ & $0.5<\varphi \leq 1.25$ & $1.25<\varphi \leq 2.5$ & $2.5<\varphi \leq 5$ & $5<\varphi \leq 10$ \\
\hline Coal (weak) & 1.28 & 1.22 & 1.17 & 1.15 & 1.14 \\
\hline Sandstone (medium hard) & 1.2 & 1.18 & 1.15 & 1.13 & 1.11 \\
\hline Limestone (hard) & 1.25 & 1.21 & 1.16 & 1.14 & 1.12 \\
\hline
\end{tabular}

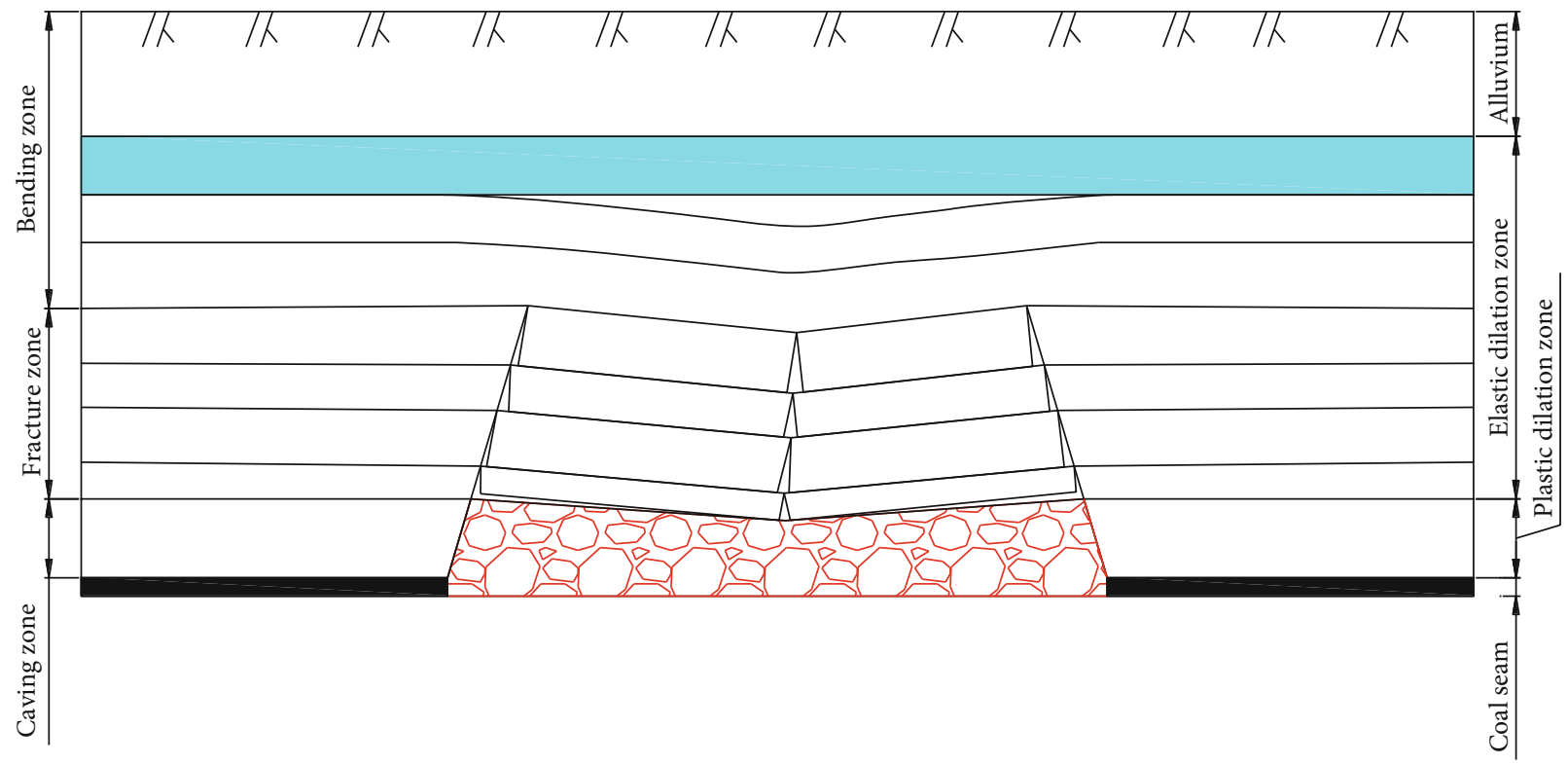

FIgURE 6: Diagram of three zone division.

be calculated according to the empirical formula given in Table 3 [38], in which $M$ is the mining height.

The bulking coefficient of the caving zone can be obtained from laboratory test results as shown in Table 4. The diameter $\varphi(\mathrm{mm})$ of the block is shown in Table 4, from which it can be seen that the coefficient of the bulking of the caving zone is between 1.1 and 1.3. With the height of the caving zone and the bulking coefficient, the breakage height of the caving zone can be calculated by the following formula:

$$
h_{\mathrm{p}}=H_{\mathrm{k}}\left(K_{\mathrm{p}}-1\right)
$$

3.1.2. Unloading Dilation of Rock Strata above the Caving Zone. Traditionally, the overburden has been transformed into the caving zone, fracture zone, and bend zone according to the fracture state. The research shows that after coal mining, the rock strata from different layers of coal seam have different dilation characteristics, and on this basis, the overburden is divided into the plastic dilation zone and the elastic dilation zone [39], as shown in Figure 6. It can be seen that the unloading dilation of rock strata above the caving zone is elastic dilation. Therefore, the unloading dilation of rock strata above the caving zone can be calculated by the coefficient of elastic dilation $K_{t}$. If the height of the elastic dilation zone is $H_{t}$, the unloading dilation of rock strata above the caving zone is

$$
h_{\mathrm{t}}=H_{\mathrm{t}}\left(K_{\mathrm{t}}-1\right) \text {. }
$$

3.2. Height of Water-Flowing Fracture Zone of the Overburden. Fractures are important channels for conducting water in layered strata. After the mining of the coal seam, the overburden will distribute fractures of different states. Among them, interconnected fractures are the way for the overburdened confined aquifer to enter the mining working faces, which will seriously threaten human and 


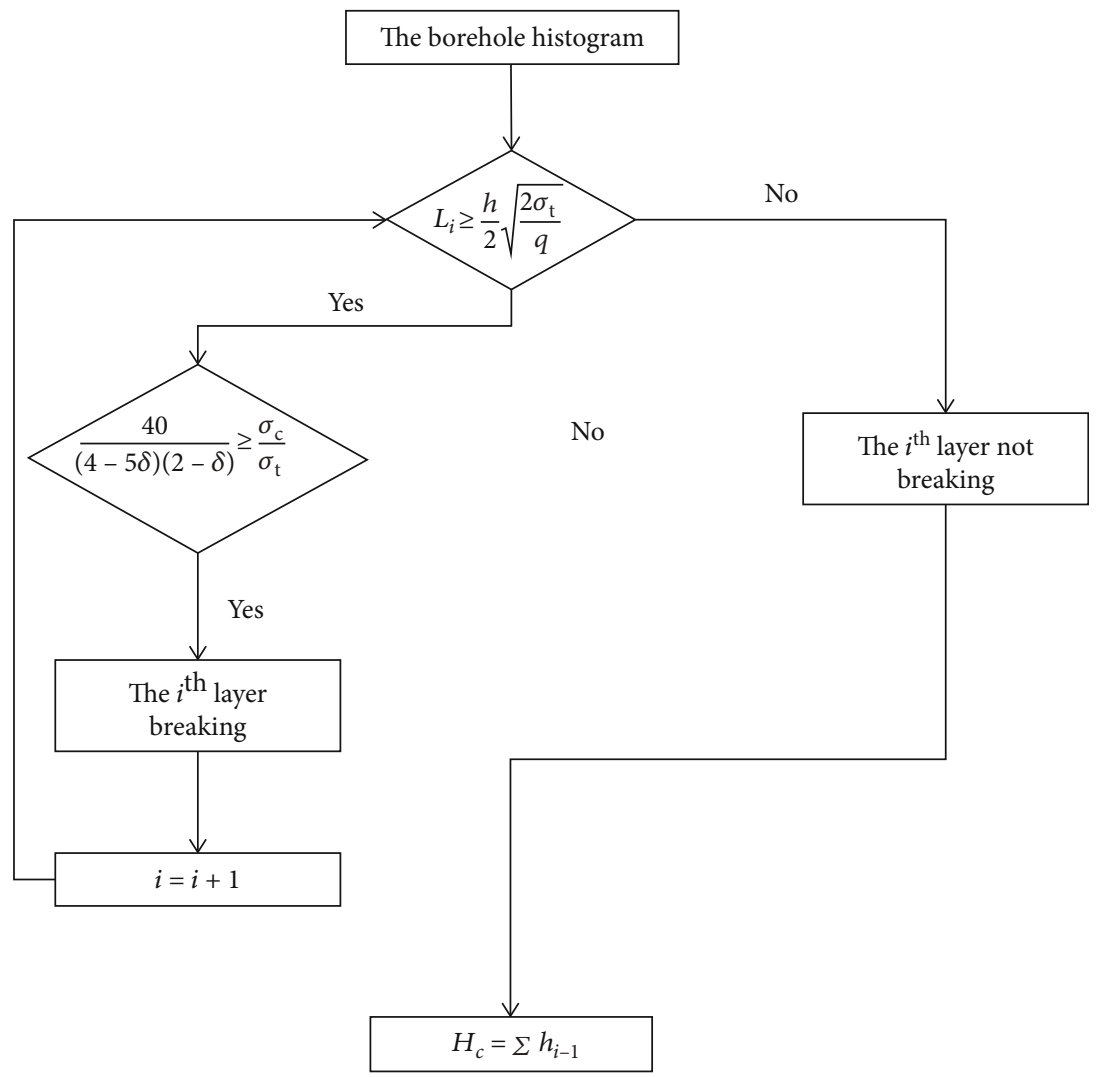

Figure 7: Discrimination process of height of water-flowing fracture zone in the overburden.

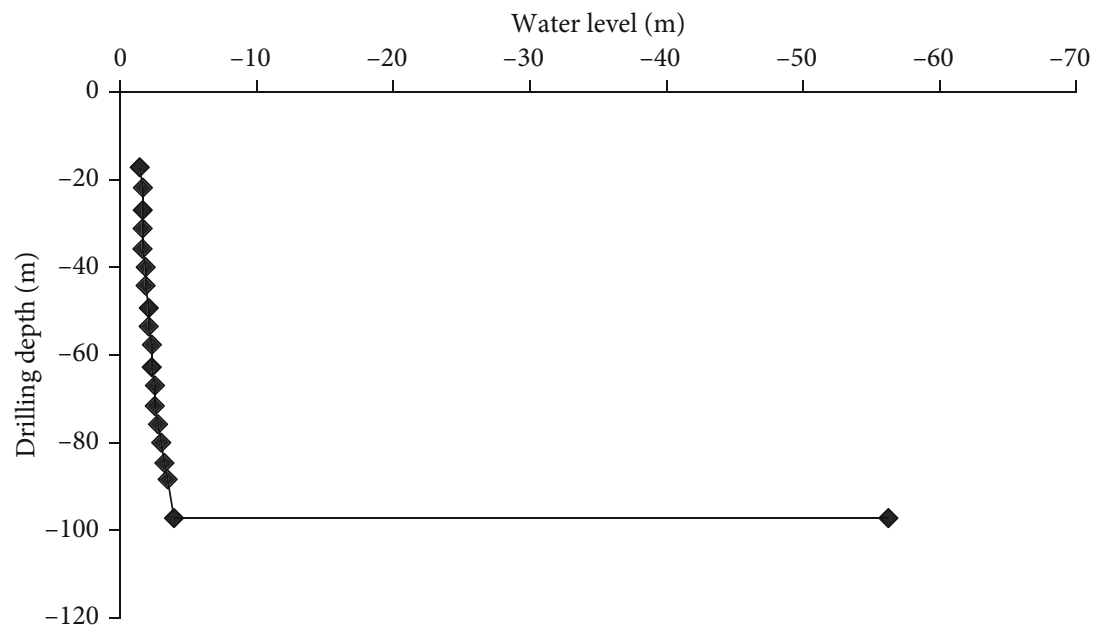

FIGURE 8: The change of water level of the drilling borehole in the water inrush area.

financial safety. Therefore, it is of great significance to predict the height of the water-flowing fracture zone for ensuring safe mining of coal mines.

There are two main methods for predicting the height of the water-flowing fracture zone. The first one is the statistical empirical formula based on a large number of measured data. This method cannot reflect the special overburden structure and breaking characteristics, and the calculation results are too small. The second method is based on the location of the PKS (will be defined fol- lowing) to predict the height of the water-flowing fracture zone, which is a lack of the interpretation of the fracture mechanics mechanism of the layered strata. In order to predict the height of the water-flowing fracture zone based on the discrimination formula of interconnected vertical fractures in this paper, the fractures of layered strata are explained in terms of mechanical mechanism.

The method of predicting the height of the water-flowing fracture zone based on the discrimination formula of interconnected vertical fractures is as follows: (1) firstly, it needs 


\begin{tabular}{|c|c|c|c|c|c|}
\hline No. & $h(\mathrm{~m})$ & $H(\mathrm{~m})$ & Lithology & KS type & Columnar \\
\hline 1 & 97.96 & 97.96 & Conglomerate & & \\
\hline 2 & 1.40 & 99.36 & Kern stone & & \\
\hline 3 & 3.87 & 103.23 & Kern stone & & \\
\hline 4 & 10.62 & 113.85 & Siltstone & & \\
\hline 5 & 8.88 & 122.73 & Argillaceous sandstone & & \\
\hline 6 & 3.86 & 126.59 & Post stone & & \\
\hline 7 & 5.90 & 132.49 & Sandy mudstone & & \\
\hline 8 & 12.92 & 145.41 & Siltstone & & \\
\hline 9 & 3.30 & 148.71 & Siltstone & & \\
\hline 10 & 32.70 & 181.41 & Medium sandstone & PKS & \\
\hline 11 & 1.18 & 182.59 & $1^{-1}$ coal & & \\
\hline 12 & 0.87 & 183.46 & Sandy mudstone & & \\
\hline 13 & 0.12 & 183.58 & Seam & & \\
\hline 14 & 1.25 & 184.83 & Sandy mudstone & & \\
\hline 15 & 0.10 & 184.93 & Seam & & \\
\hline 16 & 4.30 & 189.23 & Siltstone & & \\
\hline 17 & 2.20 & 191.43 & Sandy mudstone & & \\
\hline 18 & 0.11 & 191.54 & Lack & & \\
\hline 19 & 2.69 & 194.23 & Sandy mudstone & & \\
\hline 20 & 0.30 & 194.53 & $1^{-2}$ up coal & & \\
\hline 21 & 9.78 & 204.31 & Siltstone & SKS & \\
\hline 22 & 9.60 & 213.91 & Mudstone & & \\
\hline 23 & 1.32 & 215.23 & Mudstone & & \\
\hline 24 & 5.92 & 221.15 & $1^{-2}$ coal & & \\
\hline
\end{tabular}

(a)

\begin{tabular}{|c|r|c|c|c|c|}
\hline No. & $h(\mathrm{~m})$ & $H(\mathrm{~m})$ & Lithology & KS type & Columnar \\
\hline 1 & 115.45 & 115.45 & Conglomerate & & \\
\hline 2 & 20.06 & 135.51 & Argillaceous siltstone & & \\
\hline 3 & 15.30 & 150.81 & Coarse-grained stone & PKS & \\
\hline 4 & 3.15 & 153.96 & Argillaceous siltstone & & \\
\hline 5 & 8.20 & 162.16 & Sandy mudstone & & \\
\hline 6 & 4.40 & 166.56 & Post stone & & \\
\hline 7 & 18.18 & 184.74 & Argillaceous sandstone & & \\
\hline 8 & 12.50 & 197.24 & Medium sandstone & SKS & \\
\hline 9 & 10.64 & 207.88 & Sandy mudstone & & \\
\hline 10 & 8.55 & 216.43 & Silty claystone & & \\
\hline 11 & 5.30 & 221.73 & Post stone & & \\
\hline 12 & 10.47 & 232.20 & Sandy mudstone & & \\
\hline 13 & 13.77 & 245.97 & Post stone & SKS & \\
\hline 14 & 4.78 & 250.75 & $1^{-2}$ coal & & \\
\hline
\end{tabular}

(b)

FIGURE 9: Histogram in water inrush and normal areas of 31401 working face of Bulianta Coal Mine [25]: (a) overburden histogram in water inrush area; (b) overburden histogram in normal area. 
TABLE 5: Values in water inrush and normal areas in 31401 working face of Bulianta Coal Mine.

\begin{tabular}{lccccccccccc}
\hline Type & $M(\mathrm{~m})$ & $H_{\mathrm{p}}(\mathrm{m})$ & $K_{\mathrm{p}}(\mathrm{m})$ & $h_{\mathrm{p}}(\mathrm{m})$ & $H_{\mathrm{t}}(\mathrm{m})$ & $K_{\mathrm{t}}(\mathrm{m})$ & $h_{\mathrm{t}}(\mathrm{m})$ & $\Delta(\mathrm{m})$ & $h(\mathrm{~m})$ & $\delta$ & $f$ \\
\hline Water inrush & 5.92 & 8.61 & 1.1 & 0.86 & 25.21 & 1.009 & 0.23 & 4.40 & 32.70 & 0.14 & 6.52 \\
Normal & 4.78 & 11.53 & 1.2 & 2.36 & 83.63 & 1.009 & 0.75 & 1.67 & 15.3 & 0.11 & 6.13 \\
\hline
\end{tabular}

to collect the borehole histogram of the mining faces and then (2) judge whether the stratum is broken according to the discrimination formula. If it is not broken, it is not included in the height of the water-flowing fracture zone. If it is broken, it will become part of the water-flowing fracture zone. The flow chart for predicting the height of the waterflowing fracture zone is shown in Figure 7.

However, according to the theory of key strata (KS), the KS refer to the hard strata which control the movement of local layers or all layers up to the surface. The former is called the subkey strata (SKS), and the latter is called the primary key strata (PKS) [32]. According to the definition of the KS, the prediction method of the height of the water-flowing fracture zone based on the discrimination formula of interconnected vertical fractures only needs to judge whether the SKS or the PKS is broken. If the SKS is broken, the strata under its control will also be broken, and the water-flowing fracture zone will develop to the bottom of the upper KS at least. If the PKS is broken, the whole overburden is broken, and the water-flowing fracture zone develops to the surface.

\section{Engineering Verification}

The Shendong Mining Area, located in the transition zone between the Maowusu Desert and the hilly and gully area of Loess Plateau, belongs to an arid area. The aquifer of the Quaternary Salawusu Formation above the bedrock beneath the desert cover contains valuable diving water, which is the only aquifer in the upper part of the coal seam currently being mined in the mining area.

The 31401 fully-mechanized mining face is the first working face of $1^{-2}$ coal mining in the fourth district, with a designed mining height of 4.5-5.0 $\mathrm{m}$ and a comprehensive mechanical mining method of full collapse with longwall retraction. The working face adopts a $4.3 / 5.5 \mathrm{~m}$ two-pillar shielded hydraulic support manufactured by JOY Company with rated working resistance of $8670 \mathrm{kN}$.

During the period from the cut line to $1600 \mathrm{~m}$ in the 31401 working face, the water inflow of the working face is normal, generally $50-80 \mathrm{~m}^{3} / \mathrm{h}$, but when the working face is advanced to $1650 \mathrm{~m}$, the water inflow of the working face reaches $200 \mathrm{~m}^{3} / \mathrm{h}$. Thereafter, in the range from $1650 \mathrm{~m}$ to $2552 \mathrm{~m}$, the roof sprinkler and seepage in the goaf have been continuous. During this period, there were two large water inrushes, and the working face was flooded in a short time, resulting in a $2 \mathrm{~m}$ depth of local water inundation, two $48 \mathrm{~h}$ shutdowns, and $400 \mathrm{~m}^{3} / \mathrm{h}$ maximum water inrush.

The borehole flushing fluid loss observation method is a traditional and reliable method to determine the depth of water-flowing fracture zone and caving zone of overlying strata after mining. The height of the water-flowing fracture zone can be directly measured through the loss of drilling fluid in the drilling process.

The water level in the drilling borehole was instantly lost from $3.85 \mathrm{~m}$ to $97.46 \mathrm{~m}$ at the bottom of the hole (Figure 8), so all the drilling fluid was lost. Through comprehensive analysis and judgment, the depth of the borehole at the top of the water-flowing fracture zone is $97.10 \mathrm{~m}$. Since the ground elevation before mining is $1305 \mathrm{~m}$, the floor elevation of the coal seam is $1061 \mathrm{~m}$, that is, the mining depth of the coal seam is $244 \mathrm{~m}$. Considering the influence of the $2.0 \mathrm{~m}$ surface subsidence and $4.4 \mathrm{~m}$ mining height of the coal seam, therefore, the height of the water-flowing fracture zone is $140.5 \mathrm{~m}$.

The research shows that the water inrush is related to the position of PKS in the overburden [25]. The position of PKS is shown in Figure 9.

According to the histogram of the working face in Figure9, the mining heights of the water inrush and the normal areas in the 31401 working face of the Bulianta Coal Mine are $5.92 \mathrm{~m}$ and $4.78 \mathrm{~m}$, respectively. In addition, the lithologies of water inrush and normal areas are medium and hard, respectively, so the height of the caving zone can be calculated separately according to Table 3 without considering its error items. The bulking coefficient of soft rock is less than that of hard rock, so the bulking coefficients of the caving zone in the water inrush zone and normal zone are 1.15 and 1.2, respectively. The height of the elastic dilation zone in the water inrush and normal areas is the distance from the PKS to the top of the caving zone. The literature research shows that the elastic dilation coefficient of different strata is between 1.0090 and 1.0097 under $16 \mathrm{MPa}$ pressure [40], and the elastic dilation coefficient is taken as 1.0090 in this paper. The calculated values of each parameter are shown in Table 5.

According to Table 5, the $f$ value of water inrush area is 6.52 , greater than that of the normal area of 6.13 , and the PKS of the water inrush area is medium sandstone, while that of normal area is coarse-grained sandstone. According to the experimental results of Table 2, the compression-tension ratio of coarse-grained sandstone is larger than that of medium sandstone, so in the water inrush area, the values more easily meet the discrimination formula (6). It is worth noting that this discrimination formula is only qualitatively verified because the beam was assumed to be two-end fixed, which makes a big difference to the outcome and will be discussed in the future.+

\section{Conclusions}

Interconnected vertical fractures are the important channel to communicate confined aquifer and the working faces. Water inrush disasters will occur when interconnected 
vertical fractures extend from the roof of the working face to the aquifer. Therefore, it is of great significance to study the evolution mechanism of interconnected vertical fractures for preventing and controlling water inrush disasters. This paper draws the following conclusions through similar simulation, theoretical analysis, and field verification methods:

(1) Vertical fractures in layered strata are initiated because the tensile stress is greater than the tensile strength, but whether fractures penetrate the layered strata is determined by the compressive strength. When the compressive stress is greater than the compressive strength, the vertical fractures will penetrate a stratum

(2) Whether a vertical fracture penetrates a stratum can be expressed by the value of the criterion of interconnected vertical fractures and compression-tension ratio of layered strata. When the value of the criterion of interconnected vertical fractures is greater than the compression-tension ratio, layered strata are broken. The value of the criterion of interconnected vertical fractures is expressed by maximum relative subsidence. The larger the maximum relative subsidence, the smaller the value of the criterion of interconnected vertical fractures

(3) The value of the criterion of interconnected vertical fractures in the water inrush area of the 31401 working face of the Bulianta Coal Mine is larger than that in the normal area, while the compression-tension ratio is smaller than that in the water inrush area, so in the water inrush area, the values more easily meet the discrimination formula (6).

\section{Data Availability}

The data in the manuscript can be available on request through Changchun He, whose email address is hechangchun1987@126.com.

\section{Conflicts of Interest}

The authors declare that they have no known competing financial interests or personal relationships that could have appeared to influence the work reported in this paper.

\section{Acknowledgments}

This work was supported by the Research Start-Up Funding of Doctors in East China University of Technology-Prediction Method of Mining Subsidence by Combining Mechanics and Geometry (No. DHBK2019235), Transformation of Scientific and Technological Achievements Programs of Higher Education Institutions in Shanxi (TSTAP) (No. 2020CG050), Special Project of 2019 Plan for the Introduction of High-Level Scientific and Technological Talents in Development Zone of Lvliang City (Development of Automatic Disassembly Platform for Hydraulic Support Pin Shaft) (No. 2019102), Science and Technology Project of Lvliang City in 2019 (Pressure
Relief and Permeability Improvement Technology by Integrated Hydraulic Flushing and Cutting for Low Permeability Coal Seam Containing Methane) (No. GXZDYF2019080), Natural Science Foundation of Shanxi Province-Mechanical Behaviour and Breaking Mechanism of Three-Axis Fracture of Weak and Fractured Coal Body in Coalbed Methane Mining (No. 201901D111330), and School-Level Teaching Reform and Innovation Projects of Luliang University in 2020 (No. JXGG202039).

\section{References}

[1] Z. Shaotong, "Research on coal supply and demand trend and development intensity of China," Coal Science and Technology, vol. 48, no. S1, pp. 85-88, 2020.

[2] L. Huang, H. Hao, X. Li, and J. Li, "Source identification of microseismic events in underground mines with interferometric imaging and cross wavelet transform," Tunnelling and Underground Space Technology, vol. 71, no. 1, pp. 318-328, 2018.

[3] L. Huang, J. Li, H. Hao, and J. Li, "Micro-seismic event detection and location in underground mines by using convolutional neural networks (CNN) and deep learning," Tunneling and underground space technology, vol. 81, no. 11, pp. 265276, 2018.

[4] D. Li, "Mining thin sub-layer as self-protective coal seam to reduce the danger of coal and gas outburst," Natural Hazards, vol. 71, no. 1, pp. 41-52, 2014.

[5] L. Shi, M. Qiu, Y. Wang, X. Qu, and T. Liu, "Evaluation of water inrush from underlying aquifers by using a modified water-inrush coefficient model and water-inrush index model: a case study in Feicheng coalfield, China," Hydrogeology Journal, vol. 27, no. 6, pp. 2105-2119, 2019.

[6] B. Zhu, L. Wu, Y. Peng, W. Zhou, and C. Chen, "Risk assessment of water inrush in tunnel through water-rich fault," Geotechnical \& Geological Engineering, vol. 36, no. 1, pp. 317-326, 2018.

[7] W. Yang, X. Yang, Z. Fang et al., "Model test for water inrush caused by karst caves filled with confined water in tunnels," Arabian Journal of Geosciences, vol. 12, no. 24, pp. 749-760, 2019.

[8] V. Palchik, "Analysis of main factors influencing the apertures of mining-induced horizontal fractures at longwall coal mining," Geomechanics and Geophysics for Geo Energy and GeoResources, vol. 6, no. 2, pp. 37-48, 2020.

[9] H. Wang, D. Zhang, X. Wang, and W. Zhang, "Visual exploration of the spatiotemporal evolution law of overburden failure and mining-induced fractures: a case study of the Wangjialing coal mine in China," Minerals, vol. 7, no. 3, pp. 35-51, 2017.

[10] C. Wang, N. Zhang, Y. Han, Z. Xiong, and D. Qian, "Experiment research on overburden mining-induced fracture evolution and its fractal characteristics in ascending mining," Arabian Journal of Geosciences, vol. 8, no. 1, pp. 13-21, 2015.

[11] V. Palchik, "Experimental investigation of apertures of mining-induced horizontal fractures," International Journal of Rock Mechanics \& Mining sciences, vol. 47, no. 3, pp. 502508, 2010.

[12] Y. Li, C. Wu, and B. Jang, "Effect of bedding plane on the permeability evolution of typical sedimentary rocks under triaxial compression," Rock Mechanics Rock Engineering, 2020. 
[13] M. Bai and D. Elsworth, "Some aspects of mining under aquifers in China," Mining Science and Technology, vol. 10, no. 1, pp. 81-91, 1990.

[14] V. Palchik, "Formation of fractured zones in overburden due to longwall mining," Environmental Geology, vol. 44, no. 1, pp. 28-38, 2003.

[15] C. O. Karacan, F. A. Ruiz, M. Cotè, and S. Phipps, "Coal mine methane: a review of capture and utilization practices with benefits to mining safety and to greenhouse gas reduction," International Journal of Coal Geology, vol. 86, no. 2-3, pp. 121-156, 2011.

[16] A. Majdi, F. P. Hassani, and M. Y. Nasiri, "Prediction of the height of destressed zone above the mined panel roof in longwall coal mining," International Journal of Coal Geology, vol. 98, no. 62, pp. 62-72, 2012.

[17] M. Rezaei, M. F. Hossaini, and A. Majdi, "A time-independent energy model to determine the height of destressed zone above the mined panel in longwall coal mining," Tunneling and underground space technology, vol. 47, no. 3, article S0886779815000097, pp. 81-92, 2015.

[18] Y. Chen, G. Zhao, S. Wang et al., "A case study on the height of a water-flowing fracture zone above undersea mining: Sanshandao gold mine," China Environmental earth sciences, vol. 78, no. 4, pp. 122.1-122.15, 2019.

[19] Y. Liu, Q. M. Liu, W. P. Li et al., "Height of water-conducting fractured zone in coal mining in the soil-rock composite structure overburdens," Environmental Geology, vol. 78, no. 7, 2019.

[20] S. Wang, X. Li, and D. Wang, "Mining-induced void distribution and application in the hydro-thermal investigation and control of an underground coal fire: a case study," Process Safety \& Environmental Protection, vol. 102, article S0957582016300908, pp. 734-756, 2016.

[21] S. Wang, X. Li, and S. Wang, "Separation and fracturing in overlying strata disturbed by longwall mining in a mineral deposit seam," Engineering Geology, vol. 226, pp. 257-266, 2017.

[22] Y. Sun, Z. Xu, and Q. Dong, "Monitoring and simulation research on development of water flowing fractures for coal mining under Xiaolangdi reservoir," Chinese Journal of Rock Mechanics and Engineering, vol. 28, no. 2, pp. 238-245, 2009.

[23] X. Wang, J. Xu, and W. Zhu, "Influence of primary key stratum structure stability on evolution of water flowing fracture," Journal of China Coal Society, vol. 37, no. 4, pp. 606-612, 2012.

[24] J. L. Xu, X. Z. Wang, W. T. Liu et al., "Influence of primary key stratum location on the height of water flowing fracture zone," Chinese Journal of Rock Mechanics and Engineering, vol. 28, no. 2, pp. 381-385, 2009.

[25] X. Miao, X. Cui, J. Wang, and J. Xu, “The height of fractured water-conducting zone in undermined rock strata," Engineering Geology, vol. 120, no. 1-4, pp. 32-39, 2011.

[26] X. Xie, L. Xibing, S. Xueyi et al., "Prediction of water-bearing fracture zone height by PCA-BP neural network model," Journal of China Safety Science, vol. 27, no. 3, pp. 100-105, 2017.

[27] Z. Hongwei, Z. Zhu, H. Bingjie et al., "An improved FOA-SVM for predicting the height of water-conducted fractures," Cssea, vol. 23, no. 10, pp. 9-14, 2013.

[28] T. Z. Yi, Q. Hongyan, and C. Yizhong, "The DM-L optimization model of water-conducting fracture zone based on sensitivity analysis," Journal of Central China Normal University (Natural Science), vol. 48, no. 5, pp. 673-676, 2014.
[29] Z. Mao, L. Wenzhe, and H. Chunjuan, "Prediction of height of water flowing fractured zone based on APSO-LSSVM model," Journal of Liaoning Technical University (Natural Science), vol. 39, no. 1, pp. 34-40, 2020.

[30] Y.-z. Luan, J.-t. Li, X.-h. Ban, C.-y. Sang, C.-q. Zhang, and D.p. Ma, "Observational research on the height of water flowing fractured zone in repeated mining of short-distance coal seams," Journal of Mining \& Safety Engineering, vol. 27, no. 1, pp. 139-142, 2010.

[31] W. Zhang, D. S. Zhang, L. X. Wu, and H. Z. Wang, "On-site radon detection of mining-induced fractures from overlying strata to the surface: a case study of the Baoshan coal mine in China," Energies, vol. 7, no. 12, pp. 8483-8507, 2014.

[32] Q. minggao and S. p. Xu jialin, "Mine pressure and strata control," China university of mining and technology press, 2010.

[33] H. zhongjie, "Dimension of angle contact surface of rotating end of loading fractured rock block," Mine pressure and roof management, pp. 29-31, 1999.

[34] M. Xiexing, "Stability analysis of the main roof during the first weighting in longwall face," journal of china university of mining and technology, no. 3, pp. 91-95, 1989.

[35] N. Brook, "The measurement and estimation of basic rock strength," Rock Testing and Site Characterization, pp. 41-66, 1993.

[36] P. R. Sheorey, "Empirical Rock Failure Criteria," CRC Press, 1997.

[37] S. Li, "Discussion on the relationship between rock tensile strength and uniaxial compressive strength," Agricultural science and technology and information, no. 14, pp. 48-49, 2012.

[38] State Bureau of Coal Industry, Regulations of buildings, water, railway and main well lane leaving coal pillar and press coal mining, Beijing: China Coal Industry Publishing House, 2000.

[39] J. Xu, Q. Wei, X. Dayang et al., "Accumulative effect of overburden strata expansion induced by stress relief," Journal of China Coal Society, vol. 45, no. 1, pp. 35-43, 2020.

[40] Z. Weibing, Y. Shengchao, and X. Jingmin, "Influence of the elastic dilatation of mining-induced unloading rock mass on the development of bed separation," Energies, vol. 11, no. 4, pp. 785-801, 2018. 